\title{
Mechanical Property Verification of CRTS III Slab Track under Train Load
}

\author{
Kunteng Zhu ${ }^{1,2, a}$, Zhiping Zeng ${ }^{1,2, b^{*}}$, Bin $\mathrm{Wu}^{1, \mathrm{c}}$ and Wei Wei ${ }^{1, d}$ \\ ${ }^{1}$ Central South University, Changsha, Hunan, China \\ ${ }^{2}$ National Engineering Laboratory for High-Speed Railway Construction, Changsha, China \\ a306353043@qq.com, b956310155@qq.com, c2747958853@qq.com, d645984212@qq.com \\ * Corresponding Author
}

Keywords: CRTS III slab track; Experiment; Finite element; Mechanical property verification

\begin{abstract}
An experiment that study on the dynamic characteristics of CRTS III slab track structure on roadbed under high-speed train load was carried out. The full-scale test model of CRTS III slab track structure had been established based on track-roadbed dynamic model test system. Test results show that after train load 7.2 million times, the stiffness of isolation layer increased by 1 time, while the performance of other parts of the track structure had little change. According to the CRTSIII slab track structure characteristics, an finite element mechanical analysis model of track structure was established, which include rail, track slab, door type steel, self-compaction concrete and base. Taking load action 0 million times, 200 million times, 400 million times and 600 million times for example, the displacement and stress of track structure could be calculated. Results show that test values and theoretical values are in good agreement.
\end{abstract}

\section{Introduction}

The application time of CRTS III slab track is short in China, and the performance of the force is widely concerned by scholars [1-4]. For the study of CRTS III slab track, using ABAQUS and MSC.FATIGUE finite element software based on the classical fatigue damage theory, the fatigue properties of CRTS III slab track was studied by The Yanping[5]. Gao Liang had made a comparative study which was made of the mechanical characteristics of two design schemes, uint style and longitudinal continued style, under the action of temperature load, vehicle load, concrete shrinkage and foundation settlement deformation through a longitudinal-transverse-vertical spatial coupled model [6]. Wei Hedao put forward an overall designing scheme about the CRTS III slab track on the basis of conclusion about track structure at home and abroad [7]. China Academy of Railway Sciences has studied reasonable stiffness of fastener, reasonable stiffness of isolated layer and static and dynamic characteristics through a longitudinal-transverse-vertical spatial coupled model [8]. In this paper, the full-scale test model of CRTS III slab track structure was established based on track-roadbed dynamic model test system, at the same time, an finite element mechanical analysis model of track structure was established. Taking load action 0 million times, 200 million times, 400 million times and 600 million times for example, the displacement and stress of track structure could be calculated. Results show that test values and theoretical values are in good agreement.

\section{The Test Model of CRTS III Slab Track on Roadbed}

The test was supported by the track-roadbed dynamic model test system in national engineering laboratory for high speed railway construction. Roadbed was filled in the model slot, and track structure was laid on the roadbed. In addition to track slab was prefabricated, the roadbed, base, self-compacting concrete was made by professional team in the laboratory, as shown in Fig. 1. 

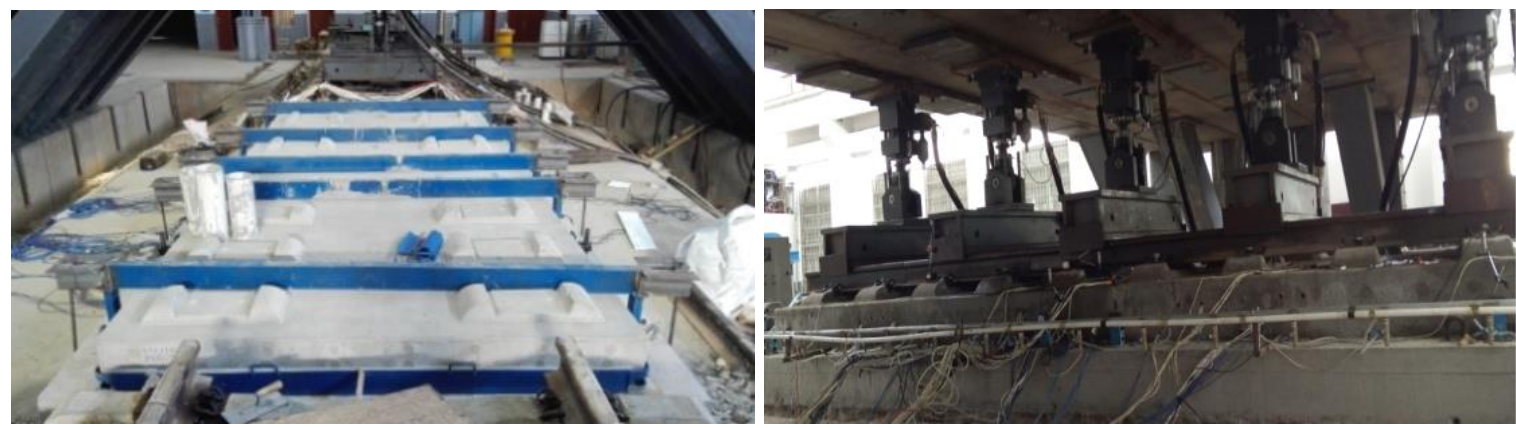

Figure 1. The test model of CRTSIII slab track structure on roadbed

\section{Test Content and Component Layout}

Test content mainly include the deformation of isolated layer (by measuring the relative displacement between the track slab and bas), acceleration (track slab and base), the strain of longitudinal and transverse (track slab, self-compacting concrete and base). Test components mainly include strain gauge, displacement transducer, acceleration transducer and so on. Specific arrangement as shown in Fig. 2. Q, F, H, S, L, T respectively stands for longitudinal 1/4 longitudinal load action point, longitudinal the middle of slab, transverse the edge of slab, longitudinal, transverse. For example, $\mathrm{H}-\mathrm{S}-\mathrm{L}$ stands for the strain of the longitudinal the middle of slab and the transverse the edge of slab.
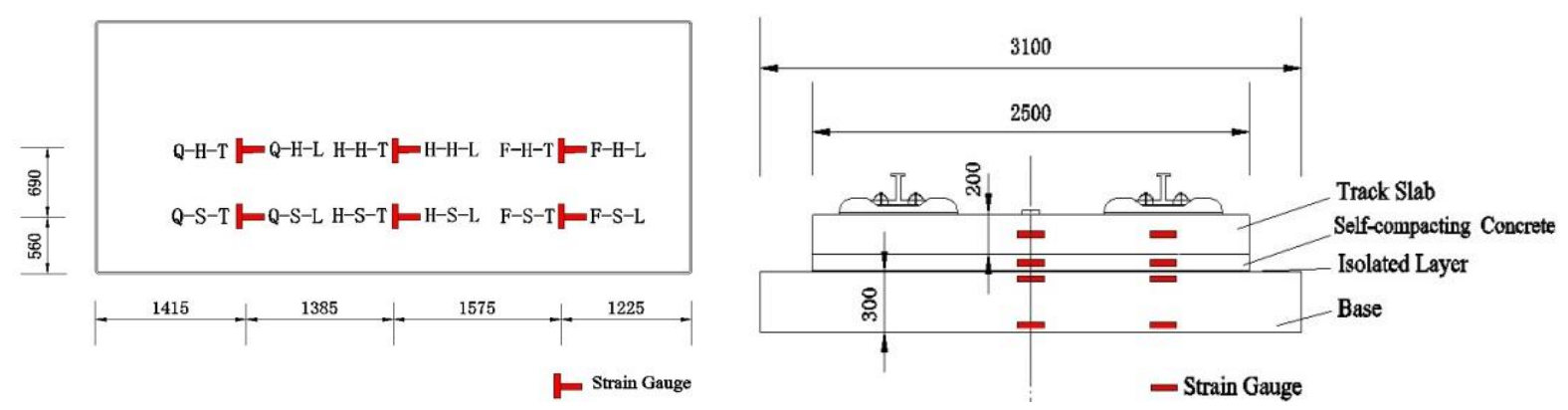

Figure 2. The layout of test element

\section{Calculation Model}

An finite element models were established using the commercial finite package ANSYS [9]. Rail was simulated by beam element. At the same time, slab, self-compacting concrete and base were simulated by 3D solid element [10], as shown in Fig. 3. In this model, the type of rail was $60 \mathrm{~kg} / \mathrm{m}$, the vertical stiffness of fastener was $50 \mathrm{kN} / \mathrm{m}$, the spacing of fasteners was $0.63 \mathrm{~m}$, the track slab was $0.2 \mathrm{~m}$ thick, $2.5 \mathrm{~m}$ wide and $5.6 \mathrm{~m}$ long, the self-compacting concrete was $0.09 \mathrm{~m}$ thick and $2.5 \mathrm{~m}$ wide, the base was $0.3 \mathrm{~m}$ thick and $3.1 \mathrm{~m}$ wide[11].
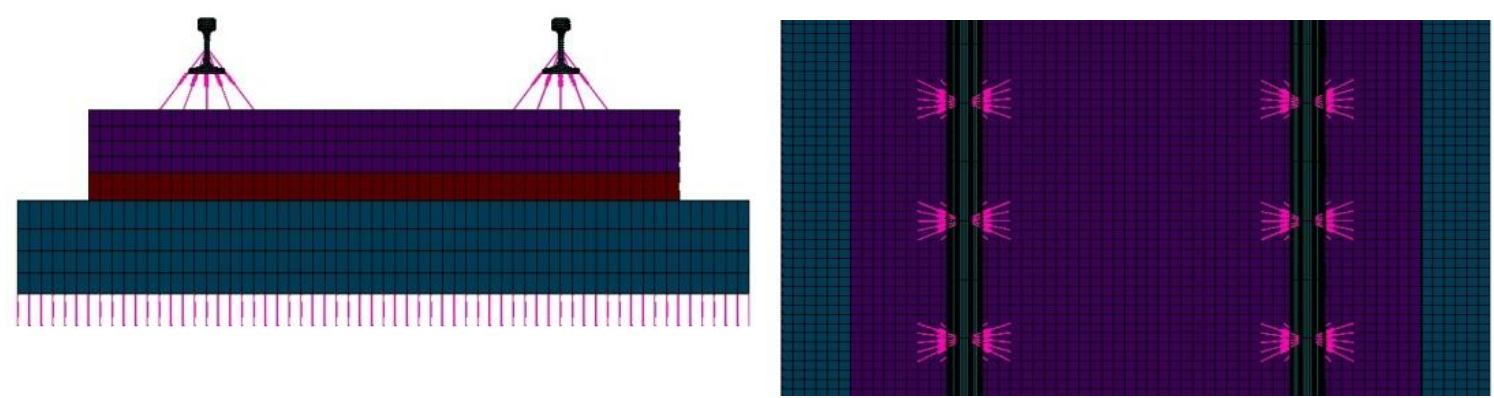

Figure 3. Finite element models 


\section{Mechanical Property Verification}

According to the results of experiment, the displacement of track slab relative to base decreased, which lead to the stiffness of isolation layer increased. However, the displacement of rail relative to track slab had small change that illustrated the stiffness of fastener had small change. The stiffness of isolation layer increased by 1times after 7.2 million fatigue load times. Therefore, the stiffness of isolation layer of the finite element model could simulate load action times.

According to the static load test force, the displacement and stress of track structure could be calculated after load action 0 times, 2 million times, 4 million times and 6 million times. Taking displacement of track slab relative to base for example, the theoretical and test values as shown in Table 1. According to Table 1, the comparison chart between the displacement of theoretical values and test values were obtained as shown in Fig. 4. Taking the tress of self-compacting concrete (H-H-T, H-H-L and H-S-L) and the stress of base (H-H-L and H-S-L) for example, the theoretical and test values as shown in Table 2 and Table 3. According to Table 3 and Table 4, the comparison chart between the stress of theoretical values and test values were obtained as shown in Fig. 5 to Fig. 7 . According to Fig. 4 to Fig. 7, we can see that the test values and theoretical values are in good agreement.

Table 1 The theoretical and test values of displacement of track slab [mm]

\begin{tabular}{|c|c|c|c|c|c|c|}
\hline \multicolumn{2}{|c|}{ Load $(\mathrm{kN})$} & 30 & 70 & 110 & 150 & 190 \\
\hline $\begin{array}{c}\text { measuring } \\
\text { point }\end{array}$ & times & $\begin{array}{c}\text { theoretical } \\
\text { values }\end{array}$ & $\begin{array}{c}\text { theoretical } \\
\text { values }\end{array}$ & $\begin{array}{c}\text { theoretical } \\
\text { values }\end{array}$ & $\begin{array}{c}\text { theoretical } \\
\text { values }\end{array}$ & $\begin{array}{c}\text { theoretical } \\
\text { values }\end{array}$ \\
\hline \multirow{3}{*}{$\begin{array}{c}\text { Displacement } \\
\text { of track slab }\end{array}$} & 0 & 0.044 & 0.075 & 0.105 & 0.138 & 0.172 \\
\cline { 2 - 7 } & 200 & 0.04 & 0.071 & 0.099 & 0.129 & 0.159 \\
\cline { 2 - 7 } & 600 & 0.03 & 0.052 & 0.075 & 0.098 & 0.118 \\
\hline & 0.023 & 0.042 & 0.062 & 0.08 & 0.098 \\
\hline \multirow{3}{*}{$\begin{array}{c}\text { Displacement } \\
\text { of track slab }\end{array}$} & 200 & 0.03 & 0.08 & 0.1 & 0.14 & 0.16 \\
\cline { 2 - 7 } & 400 & 0.03 & 0.07 & 0.1 & 0.12 & 0.14 \\
\cline { 2 - 7 } & 600 & 0.01 & 0.03 & 0.05 & 0.07 & 0.08 \\
\hline
\end{tabular}

Table 2 The theoretical values of stress of track structure [MPa]

\begin{tabular}{|c|c|c|c|c|c|c|}
\hline \multicolumn{2}{|c|}{ Load $(\mathrm{kN})$} & 30 & 70 & 110 & 150 & 190 \\
\hline $\begin{array}{c}\text { measuring } \\
\text { point }\end{array}$ & times & $\begin{array}{c}\text { theoretical } \\
\text { values }\end{array}$ & $\begin{array}{c}\text { theoretical } \\
\text { values }\end{array}$ & $\begin{array}{c}\text { theoretical } \\
\text { values }\end{array}$ & $\begin{array}{c}\text { theoretical } \\
\text { values }\end{array}$ & $\begin{array}{c}\text { theoretical } \\
\text { values }\end{array}$ \\
\hline \multirow{4}{*}{ H-H-L(S) } & 0 & 0.174 & 0.268 & 0.362 & 0.454 & 0.548 \\
\cline { 2 - 7 } & 200 & 0.171 & 0.262 & 0.353 & 0.443 & 0.534 \\
\cline { 2 - 7 } & 400 & 0.162 & 0.236 & 0.323 & 0.409 & 0.492 \\
\cline { 2 - 7 } & 600 & 0.152 & 0.223 & 0.303 & 0.382 & 0.469 \\
\hline \multirow{4}{*}{ H-S-L(S) } & 0 & 0.24 & 0.412 & 0.584 & 0.756 & 0.939 \\
\cline { 2 - 7 } & 200 & 0.19 & 0.407 & 0.579 & 0.751 & 0.923 \\
\cline { 2 - 7 } & 600 & 0.214 & 0.387 & 0.558 & 0.73 & 0.866 \\
\hline \multirow{5}{*}{ H-S-L(B) } & 000 & 0.199 & 0.376 & 0.545 & 0.711 & 0.822 \\
\cline { 2 - 7 } & 200 & 0.091 & 0.121 & 0.151 & 0.181 & 0.211 \\
\cline { 2 - 7 } & 400 & 0.106 & 0.129 & 0.163 & 0.197 & 0.231 \\
\cline { 2 - 7 } & 600 & 0.112 & 0.149 & 0.194 & 0.24 & 0.287 \\
\hline
\end{tabular}


Table 3 The theoretical values of stress of track structure [MPa]

\begin{tabular}{|c|c|c|c|c|c|c|}
\hline \multicolumn{2}{|c|}{ Load (kN) } & 30 & 70 & 110 & 150 & 190 \\
\hline $\begin{array}{c}\text { measuring } \\
\text { point }\end{array}$ & times & $\begin{array}{c}\text { test } \\
\text { values }\end{array}$ & $\begin{array}{c}\text { test } \\
\text { values }\end{array}$ & $\begin{array}{c}\text { test } \\
\text { values }\end{array}$ & $\begin{array}{c}\text { test } \\
\text { values }\end{array}$ & $\begin{array}{c}\text { test } \\
\text { values }\end{array}$ \\
\hline \multirow{4}{*}{ H-H-L(S) } & 0 & 0.17 & 0.272 & 0.374 & 0.476 & 0.544 \\
\cline { 2 - 7 } & 200 & 0.17 & 0.272 & 0.34 & 0.442 & 0.51 \\
\cline { 2 - 7 } & 400 & 0.136 & 0.238 & 0.306 & 0.374 & 0.442 \\
\cline { 2 - 7 } & 600 & 0.102 & 0.204 & 0.272 & 0.34 & 0.408 \\
\hline \multirow{4}{*}{ H-S-L(S) } & 0 & 0.204 & 0.408 & 0.544 & 0.714 & 0.918 \\
\cline { 2 - 7 } & 200 & 0.204 & 0.408 & 0.578 & 0.714 & 0.884 \\
\cline { 2 - 7 } & 400 & 0.204 & 0.374 & 0.51 & 0.714 & 0.782 \\
\cline { 2 - 7 } & 600 & 0.204 & 0.374 & 0.51 & 0.646 & 0.748 \\
\hline \multirow{4}{*}{ H-H-L(B) } & 0 & 0.068 & 0.102 & 0.136 & 0.17 & 0.204 \\
\cline { 2 - 7 } & 200 & 0.068 & 0.102 & 0.17 & 0.204 & 0.238 \\
\cline { 2 - 7 } & 400 & 0.068 & 0.102 & 0.17 & 0.238 & 0.272 \\
\cline { 2 - 7 } & 600 & 0.068 & 0.136 & 0.204 & 0.272 & 0.306 \\
\hline
\end{tabular}

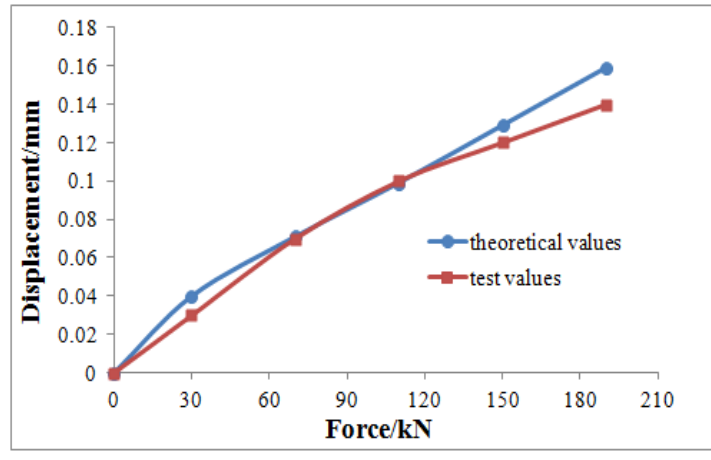

(a) 200 million times

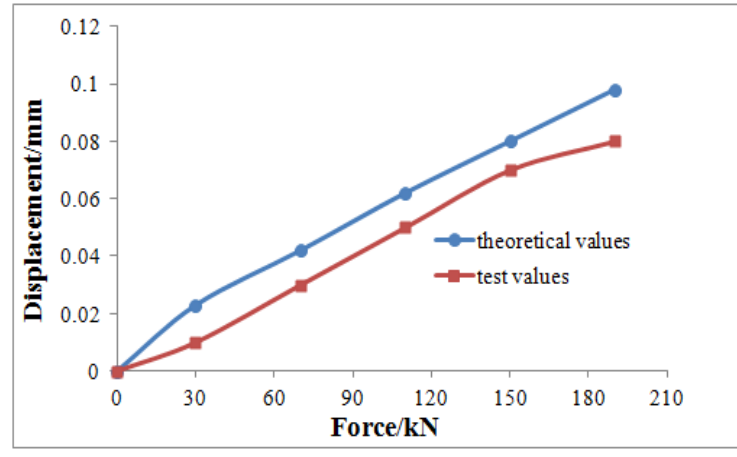

(b) 600 million times

Figure 4. Comparison chart between the displacement of test values and theoretical values

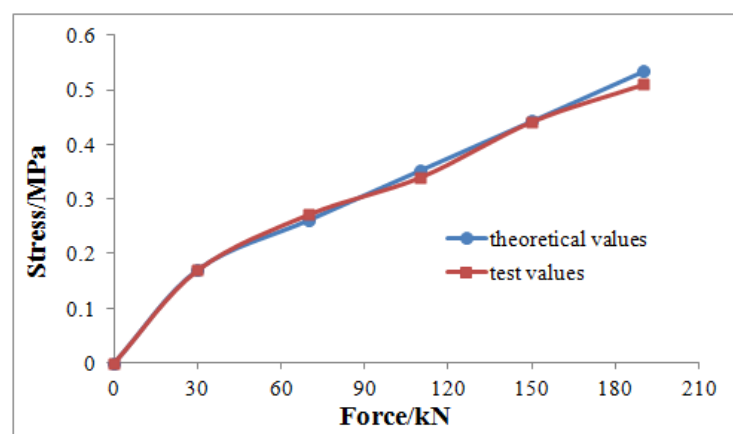

(a) 200 million times

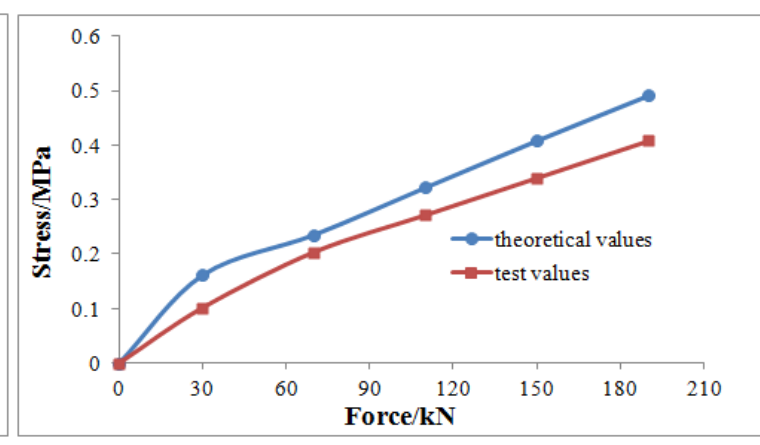

(b) 600 million times

Figure 5. Comparison chart between the stress $(\mathrm{H}-\mathrm{H}-\mathrm{L}(\mathrm{S}))$ of test values and theoretical values 


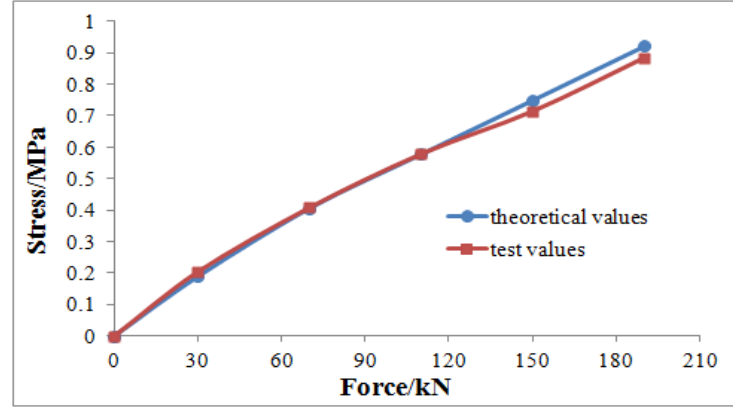

(a) 200 million times

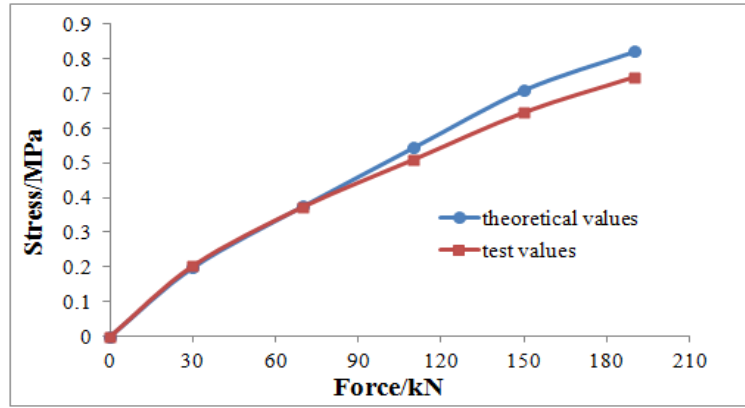

(b) 600 million times

Figure 6. Comparison chart between the stress $(\mathrm{H}-\mathrm{S}-\mathrm{L}(\mathrm{S}))$ of test values and theoretical values

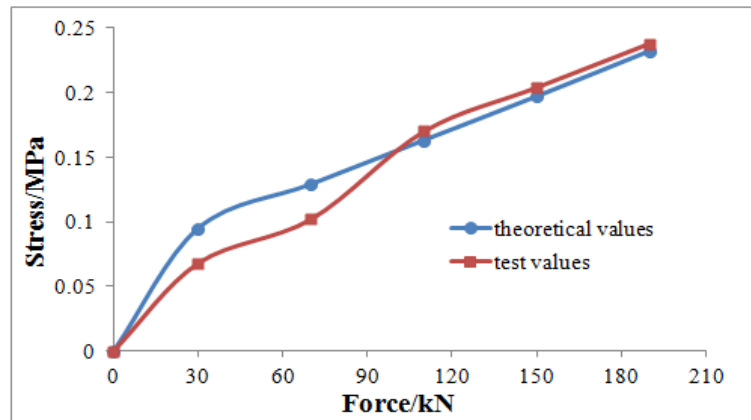

(a) 200 million times

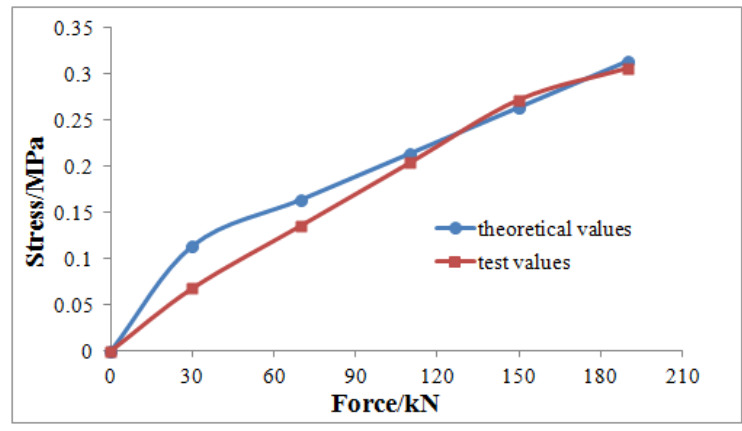

(b) 600 million times

Figure 7. Comparison chart between the stress (H-H-L (B)) of test values and theoretical values

\section{Conclusions}

The stiffness of the isolation layer increased with the increasing of the train load times, which may lead to the stress and acceleration of base have substantial increase. It can also have adverse effects on the fatigue performance of the base and the stability of the roadbed.

Taking load action 0 million times, 200 million times, 400 million times and 600 million times for example, the displacement and stress of track structure could be calculated. Results show that test values and theoretical values are in good agreement.

We can analysis the mechanical property of CRTS III slab track through finite element models.

\section{Acknowledgements}

The research described in this paper was financially supported by the Science and Technology Foundation of China Railway Corporation (Grant No. 2014G001-D); the Joint Fund of the National Natural Science Foundation of China (Grant No. U1334203); the National Natural Science Foundation of China (Grant No. 51378513); the Project of Innovation-driven Plan in Central South University (2015CXS014).

\section{References}

[1] WANG Yuhang, WANG Jijun. Multi-scale Finite Element Model for CRTS III Type Slab Ballastless Track Structures [J]. Journal of Railway Science and Engineering, 2015, 12(3): 468-474.

[2] SUN Lu, DUAN Yufen, YANG Xin. Static Response Analysis of CRTS III Type Slab Ballastless Track [J]. Journal of Railway Engineering Society, 2013, 16(11): 32-39. 
[3] MAN Kunlin, LONG Guangcheng, Xie Youjun. Carbonation and Mechanics Evolvement of Self-consolidating Concrete Used in CRTS III Type Slab Ballastless Track Filling Layer [J]. Journal of Railway Science and Engineering, 2012, 9(6): 42-47.

[4] ZHOU Yi. Research on Vibration-reduction Performance of CRTS III Type Slab Ballastless Track [D]. Chengdu: Southwest Jiaotong University, 2009.

[5] HE Yanping. Study on Fatigue Property of CRTS III Type Slab Ballastless Track [D]. Chengdu: Southwest Jiaotong University, 2011.

[6] GAO Liang, ZHAO Lei, QU Cun, CAI Xiaopei. Analysis on Design Scheme of CRTS III Type Slab Ballastless Track [J]. Journal of Tongji University (Natural Science), 2013, 41(6): 848-855.

[7] WEI Hedao. Research on the Structure Design of New Unit Slab Ballastelss Track on the Zhengzhou-Xuzhou Railway Passenger Dedicated Line [D]. Changsha: Central South University, 2013.

[8] China Academy of Railway Sciences, Southwest Jiaotong University, Beijing Jiaotong University. Theory and Further Study on the Main Parts of CRTS III Type Slab Ballastless Track[R]. Beijing: China Academy of Railway Sciences, 2014.

[9] Wang Xinmin. Numerical Analysis of Ansys Engineering structure [M]. Beijing: China Communications Press, 2007.

[10] Yang Zheng. Mechanics and Maintenance Standards of Connection Damage for CRTS III Slab Track [D]. Chengdu: Southwest Jiaotong University, 2011.

[11] China Academy of Railway Sciences. General Reference Map of High Speed Railway CRTS III Type Slab Ballastless Track Structures[S]. Beijing: China Academy of Railway Sciences, 2015. 